\title{
Effectiveness and Safety of Pressure Dressings on Reducing Subdural Effusion After Decompressive Craniectomy
}

\author{
Wanyong Huang (D) \\ Bo Zhou* \\ Yingwei Li* \\ Yuansheng Shao \\ Bo Peng \\ Xianchun Jiang \\ Tao Xiang
}

Department of Neurosurgery, People's Hospital of Guanghan City, Guanghan City, Sichuan Province, People's Republic of China

*These authors contributed equally to this work
Correspondence: Wanyong Huang Department of Neurosurgery, People's Hospital of Guanghan City, 75 Hankou Road, Luocheng Town, Guanghan City, Sichuan Province, People's Republic of China

Email huangwy459088699@163.com
Objective: Decompressive craniectomy as a treatment is often used in the rescue treatment of critically ill patients in neurosurgery; however, there are many complications after this operation. Subdural effusion is a common complication after decompressive craniectomy. Once it occurs, it can cause further problems for the patient. Therefore, the purpose of this study was to explore the safety and effectiveness of pressure dressings for subdural effusion after decompressive craniectomy.

Methods: Patients who underwent decompressive craniectomy in our hospital from January 2016 to January 2021 were included in this study, and all patients were followed up for 6 months or more. After the operation, the patients were divided into two groups according to whether they received a pressure dressing or a traditional dressing. Subdural effusion, cerebrospinal fluid leakage, hydrocephalus and other complications were compared between the two groups, and the differences in hospital duration, cost and prognosis between the two groups were analyzed.

Results: A total of 123 patients were included in this study. Among them, 62 patients chose pressure dressings, and 61 patients chose traditional dressings. The incidence of subdural effusion in the pressure dressing group was significantly lower than that in the traditional dressing group $(\mathrm{P}<0.05)$. There was no difference between the two groups in cerebrospinal fluid leakage and hydrocephalus $(\mathrm{P}>0.05)$. In addition, the length of hospital stay and the total cost in the pressure dressing group were significantly lower $(\mathrm{P}<0.05)$.

Conclusion: Pressure dressing can effectively reduce the occurrence of subdural effusion after decompressive craniectomy, and it does not increase the occurrence of other cerebrospinal fluid-related complications.

Keywords: decompressive craniectomy, complication, pressure dressing, subdural effusion

\section{Introduction}

Increased intracranial pressure often seriously threatens the lives of patients; neurosurgery, intracerebral hemorrhage (ICH) and traumatic brain injury (TBI) are the most common causes of increased intracranial pressure (ICP). ${ }^{1}$ When the ICP rises, the compliance of the brain blood vessels, the oxygenation capacity of the brain tissue, and brain blood perfusion will all change. If intracranial hypertension cannot be treated in a timely and effective manner, the patient's condition will worsen, brain herniation will develop, and even death can occur. ${ }^{2}$ Therefore, once the ICP increases, active treatment is required. In clinical work, we often use drugs such as mannitol to reduce ICP; however, for patients with malignant high 
ICP or even brain herniation, surgical intervention is required. ${ }^{3}$ Decompressive craniectomy (DC) has undergone decades of development and application and has become an important method for neurosurgery to resolve intracranial hypertension. ${ }^{3,4}$ DCs can increase the space occupied by brain tissue, so they can effectively reduce ICP, thereby improving abnormal brain physiological functions caused by increased ICP. ${ }^{5}$

Although DC can obviously save the lives of most patients, as a rescue operation method, it has many disadvantages. ${ }^{6}$ There are various complications after DC, and the overall incidence of these complications is quite high; therefore, they often cause severe problems for patients and cause serious social and economic burdens. ${ }^{7}$ Regarding the probability of these complications, the most common complications after DC mainly include postoperative hemorrhage, postoperative infection, hydrocephalus, subdural effusion, cerebrospinal fluid (CSF) leakage/fistula formation, and so on. ${ }^{8-10}$ Among these complications, the incidence of subdural effusion is $12.5 \%-27.4 \%,{ }^{11}$ and it occurs more frequently in children, with an incidence as high as $57.1 \%{ }^{12}$ Once subdural effusion has formed, neurosurgeons will have to face another difficult challenge; therefore, it is extremely important to prevent the occurrence of subdural effusion after DC. Although there are several ways to reduce the occurrence of subdural effusion (for example, dense meningeal repair during DC and early cranioplasty), these methods cannot be applied to every patient undergoing DC. Xu et $\mathrm{al}^{13}$ found that using pressure dressings after DC in TBI patients can prevent the occurrence of subdural effusion. Their study only included patients with TBI, and it is still unknown whether pressure dressings can prevent subdural effusion in patients undergoing DC due to other causes. Moreover, they did not explore whether using a pressure dressing after DC would increase the risk of other complications related to CSF circulation disorders.

The purpose of our study was to further clarify whether pressure dressings can prevent the occurrence of subdural effusion after DC. At the same time, it is not clear whether the pressure dressing will affect the outcome of other cerebrospinal fluid-related complications after DC.

\section{Methods}

\section{Subjects of the Study}

The subjects of our study were all patients who received DC in the Department of Neurosurgery, People's
Hospital of Guanghan City, from January 2016 to January 2021. We excluded patients who were younger than 18 years old and older than 80 years old, had a follow-up time $<6$ months, had incomplete clinical data, had subdural effusion that occurred immediately after DC (within 3 days after DC), had significantly elevated skin flap tension, and refused to be followed up in this study. We use computers to allocate random sequences. These patients were divided into an experimental group (pressure dressing group) and a control group (traditional dressing group). The family members of all patients signed informed consent forms. Our study followed the STROBE statement. The study was approved by the People's Hospital of Guanghan City Ethics Committee.

\section{Data Collection and Outcome Assessment}

When patients were admitted to the hospital, we recorded their clinical characteristics and demographics, including the following: age, sex, preoperative Glasgow Coma Scale (GCS) score, preoperative/intraoperative diagnosis (ICH or TBI), degree of preoperative midline displacement presence of a reoperative intracranial hemorrhage, surgical side (left, right, or both sides), and postoperative dressing of the skull defect (pressure dressing or traditional dressing). Complications related to postoperative CSF circulation disorders were also recorded, including subdural effusion, thickness of subdural effusion, time of appearance of subdural effusion (days after operation), time of subdural effusion disappearance (time from appearance to disappearance of effusion), subdural hygroma, and CSF leakage/fistula formation. In addition, we also recorded other information, including the length of hospitalization ( $<30$ days or $\geq 30$ days) and the total cost of hospitalization. All patients were followed up by telephone to assess their recovery at 6 months after DC, and their long-term outcomes were assessed using the Glasgow Outcome Scale (GOS) (Table 1). In addition, we defined new subdural effusions with a thickness of more than $2 \mathrm{~mm}$ found in the re-examination of a head CT scan after the DC operation as subdural effusion complicated by the DC operation.

All of the patients underwent DC surgery performed by highly experienced and well-trained neurosurgeons in our hospital. For patients receiving pressure dressings after the DC operation, we started to use elastic bandages to dress 
Table I Glasgow Outcome Scale (Glasgow Outcome Scale, GOS)

\begin{tabular}{|l|l|}
\hline Score & Description \\
\hline 1 & Death \\
2 & Vegetative state \\
3 & Severe disability \\
4 & Moderate disability \\
5 & Good recovery \\
\hline
\end{tabular}

the skull defect from the 4th to the 7th day after the operation (usually dressing after the patient's intracranial drainage tube was removed), and the restraint pressure of the elastic bandage was medium strength. In the subsequent treatment process, the restraint pressure of the elastic bandage was appropriately adjusted according to the patient's condition. For those patients who were unwilling to accept pressure dressings, we used traditional dressings. Except for other special circumstances, all patients received basically the same treatment after DC.

\section{Statistical Analyses}

All the data we collected were analyzed using SPSS version 24.0 (IBM, Armonk, New York, USA). All analyses were performed between the pressure dressing group and the traditional dressing group. We used the mean \pm standard deviation to represent continuous variables (age, preoperative Glasgow score, preoperative midline shift, preoperative intracranial hemorrhage, etc.). Categorical variables are expressed in numbers and percentages (, sex, side of operation, occurrence of subdural effusion, etc.). After passing the Kolmogorov-Smirnov test for the normality of continuous variables, the $t$-test was used to compare the pressure dressing group and the traditional dressing group; for the comparison between categorical variables, Pearson's $\chi^{2}$ test or Fisher's exact test was used. The difference was considered statistically significant when $\mathrm{P} \leq 0.05$.

\section{Results}

\section{Clinical Characteristics}

A total of 159 patients received DC treatment at People's Hospital of Guanghan City from January 2016 to January 2021. Among them, 20 patients died early after the DC operation, 4 patients were transferred to a higher-level hospital after the operation, and 12 patients refused to follow up or were lost to follow-up. Among the patients with subdural effusion after the DC operation, 4 patients did not
Table 2 Clinical Characteristics and Demographic Data of the Pressure Dressings Group and the Traditional Dressings Group

\begin{tabular}{|l|l|l|l|}
\hline Variable & $\begin{array}{l}\text { Pressure } \\
\text { Dressing }\end{array}$ & $\begin{array}{l}\text { Traditional } \\
\text { Dressing }\end{array}$ & P value \\
\hline $\begin{array}{l}\text { Gender } \\
\text { Male } \\
\text { Female }\end{array}$ & 47 & 44 & $0.642^{\mathrm{a}}$ \\
\hline Age (years) mean \pm SD & $53 \pm 13$ & $53 \pm 12$ & $0.938^{\mathrm{b}}$ \\
\hline Preoperative GCS mean \pm SD & $6 \pm 1$ & $6 \pm 2$ & $0.486^{\mathrm{b}}$ \\
\hline $\begin{array}{l}\text { Preoperative or } \\
\text { intraoperative diagnosis } \\
\text { Intracerebral } \\
\text { hemorrhage } \\
\text { Traumatic brain injury }\end{array}$ & 50 & 12 & $0.363^{\mathrm{a}}$ \\
\hline $\begin{array}{l}\text { Preoperative midline } \\
\text { displacement }\end{array}$ & $0.7 \pm 0.3$ & $0.7 \pm 0.2$ & $0.988^{\mathrm{b}}$ \\
\hline $\begin{array}{l}\text { Preoperative intracranial } \\
\text { hemorrhage volume }\end{array}$ & $54 \pm 10$ & $55 \pm 16$ & $0.058^{\mathrm{b}}$ \\
\hline $\begin{array}{l}\text { Surgical side } \\
\text { Left } \\
\text { Right }\end{array}$ & 30 & 22 & $0.167^{\mathrm{a}}$ \\
\hline
\end{tabular}

Notes: ${ }^{\text {ap }}$ value: Pearson's $\chi^{2}$ test or Fisher's exact test; ${ }^{\mathrm{b}} \mathrm{P}$ value: $t$-test.

completely disappear until the end of follow-up. In the end, a total of 123 patients were included in this study. Among them, 62 patients chose postoperative pressure dressings, and 61 patients chose traditional dressings. Among these patients, there were 35 cases of ICH and 88 cases of TBI.

The clinical characteristics and demographic data of these patients are shown in Table 2. The data results showed that there were no significant differences in age, sex, preoperative GCS score, preoperative/intraoperative diagnosis, preoperative midline displacement, preoperative intracranial hemorrhage volume, or surgical side (left, right or bilateral) between the pressure dressing group and the traditional dressing group $(\mathrm{P}>0.05)$.

\section{Complications of CSF After DC}

Among the cerebrospinal fluid-related complications, there were 7 patients with subdural effusion in the pressure dressing group and 17 patients with subdural effusion in the traditional dressing group. There was a significant difference between the two groups $(\mathrm{P}<0.05)$. However, there was no significant difference in other cerebrospinal fluid disorderrelated complications, such as CSF leakage and hydrocephalus $(\mathrm{P}>0.05)$. The cerebrospinal fluid-related complications in the pressure dressings group and the traditional dressings 
Table 3 Shows the Cerebrospinal Fluid-Related Complications in the Pressure Dressings Group and the Traditional Dressings Group

\begin{tabular}{|l|l|l|l|}
\hline Variable & $\begin{array}{l}\text { Pressure } \\
\text { Dressing }\end{array}$ & $\begin{array}{l}\text { Traditional } \\
\text { Dressing }\end{array}$ & P value \\
\hline $\begin{array}{c}\text { Subdural effusion } \\
\text { Yes }\end{array}$ & 7 & 17 & 0.020 \\
No & 55 & 44 & \\
\hline $\begin{array}{c}\text { Hydrocephalus } \\
\text { Yes }\end{array}$ & 11 & $5 \mathrm{I}$ & 0.966 \\
No & 11 & 50 & \\
\hline $\begin{array}{c}\text { CSF leakage } \\
\text { Yes }\end{array}$ & 8 & 7 & 0.809 \\
No & 54 & 54 & \\
\hline
\end{tabular}

Notes: $P$ value: Pearson's $\chi^{2}$ test or Fisher's exact test. Abbreviation: CSF, cerebrospinal fluid.

group are shown in Table 3. Compared with the pressure dressing group, the traditional dressing group was more likely to have subdural effusion after the DC operation. Compared with the traditional dressing group, the pressure dressing group did not experience significantly increased occurrences of subdural effusion after DC The CT findings of subdural effusion after DC in the pressure dressing group are shown in Figure 1, and those of the traditional dressing group are shown in Figure 2.

\section{Other Data}

In addition, we also analyzed the length of hospital stay ( $<30$ days or $\geq 30$ days) and the total hospitalization

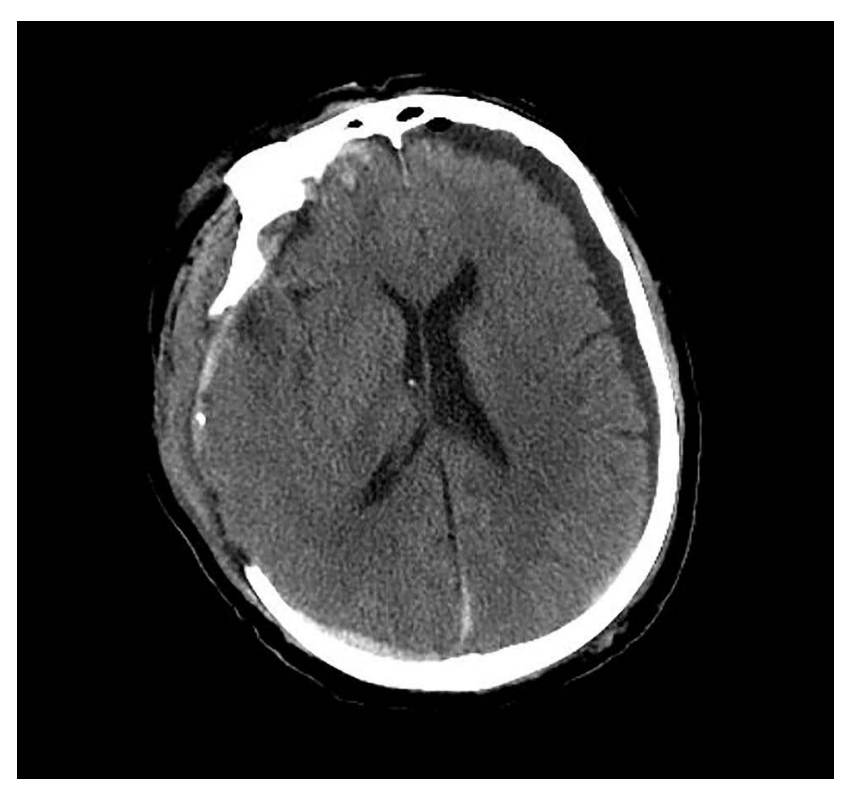

Figure I CT findings of subdural effusion after DC in the pressure dressings group.

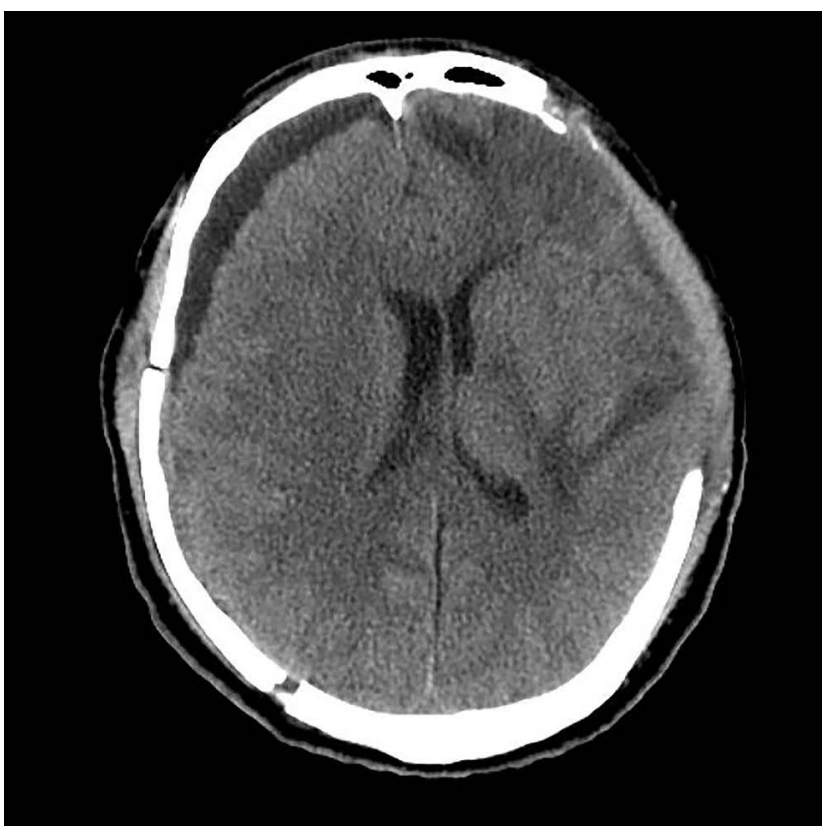

Figure $2 \mathrm{CT}$ findings of subdural effusion after $\mathrm{DC}$ in the traditional dressings group.

expenses of the pressure dressing group and the traditional dressing group and found that there were significant differences between the two groups $(\mathrm{P}<0.05)$ (Table 4). In terms of the prognosis of the patients, there was no significant difference in GOS score between the two groups $(\mathrm{P}>0.05)$.

\section{Discussion}

We conducted a retrospective analysis of 123 patients who underwent DC surgery in the Department of Neurosurgery at our hospital and found that the incidence of subdural effusion after DC surgery in the pressure dressing group

Table 4 Length of Hospital Stay, Total Hospital Expenses and Prognosis of the Pressure Dressings Group and the Traditional Dressings Group

\begin{tabular}{|c|c|c|c|}
\hline Variable & $\begin{array}{l}\text { Pressure } \\
\text { Dressing }\end{array}$ & $\begin{array}{l}\text { Traditional } \\
\text { Dressing }\end{array}$ & $P$ value \\
\hline $\begin{array}{l}\text { Length of hospital stay } \\
\qquad 30 \text { days } \\
\geq 30 \text { days }\end{array}$ & $\begin{array}{l}19 \\
43\end{array}$ & $\begin{array}{l}9 \\
52\end{array}$ & $0.036^{\mathrm{a}}$ \\
\hline $\begin{array}{l}\text { Total hospitalization } \\
\text { expenses mean } \pm S D \\
\text { (Unit: ten thousand } \\
\text { yuan) }\end{array}$ & $11.7 \pm 3.7$ & $13.6 \pm 5.9$ & $0.034^{b}$ \\
\hline GOS mean $\pm S D$ & $3.4 \pm I .1$ & $3.2 \pm 1.1$ & $0.404^{b}$ \\
\hline
\end{tabular}

Notes: ${ }^{\text {ap }} \mathrm{P}$ value: Pearson's $\chi^{2}$ test or Fisher's exact test; ${ }^{\text {b }} \mathrm{P}$ value: $t$-test. 
was significantly lower than that of the traditional dressing group, but pressure dressings did not increase the occurrence of CSF leakage and hydrocephalus. In addition, the length of hospital stay in the pressure dressing group was shorter, and the total hospitalization cost was lower than that in the traditional dressing group. The use of a pressure dressing did not have an adverse effect on the patient's prognosis.

At present, many studies have shown that DC can effectively reduce intracranial pressure, reduce the mortality of patients, and save more lives. ${ }^{3,6,14}$ However, there are many complications after a DC operation, and the incidence of these complications is also quite high. ${ }^{4}$ In the past, we often only paid attention to the benefits of DC to patients and ignored the existence of these complications. As people pay more attention to the long-term prognosis and quality of life of these patients, related complications after DC surgery have gradually attracted people's attention. However, the occurrence of these complications will not only pose a huge challenge to neurosurgeons but also increase the financial and mental burdens for the patient's family. ${ }^{15,16}$ Complications related to $\mathrm{CSF}$ circulation disorders are very common postoperative complications after DC and mainly include CSF leakage, hydrocephalus and subdural effusion. Once complications related to CSF circulation disorders occur, it is quite difficult to solve these problems under the existing technical conditions. ${ }^{9,17,18}$ Therefore, preventing the occurrence of complications related to CSF circulation disorders has become very important during the entire treatment process of patients.

The incidence of subdural effusion after DC is very high; however, the mechanism of the formation of subdural effusion after DC is still unclear. The possible reasons for its formation are as follows: the junction between the dura and the arachnoid is only a thin layer of collagen and cells, and the structure of these junctions is very loose; therefore, this thin-layer structure is quite fragile at the anatomical level, and it is very easily destroyed when subjected to external forces. ${ }^{19,20}$ The effect of external force can also cause changes in the function of intracranial capillaries (increased osmotic pressure), and the osmotic pressure of the subdural space changes with changes in capillary osmotic pressure. $^{21}$ The destruction of the arachnoid membrane can also lead to the formation of a one-way valve at the damaged site, which makes the cerebrospinal fluid flow continuously into the subdural space. ${ }^{22-24}$ Preoperative midline displacement, preoperative basal cistern compression, etiology, and the formation of postoperative hydrocephalus are often related to the occurrence of subdural effusion after DC. ${ }^{25}$ During the implementation of DC surgical treatment, various anatomical structures are often destroyed. Intraoperative and postoperative changes in physiological functions, such as intracranial pressure, will also lead to changes in capillary permeability. Changes in various anatomical structures and physiological functions will lead to cerebrospinal fluid circulation obstacles and eventually lead to the formation of subdural effusion.

Currently, the treatment options for subdural effusion after DC are very limited. In terms of drug treatment, acetazolamide or atorvastatin can be used for treatment. $^{26}$ In terms of surgical treatment, a subdural puncture drainage of an effusion, a thoracic or abdominal cavity shunt, and early cranioplasty can be adopted. ${ }^{27,28}$ However, regardless of which kind of treatment we adopt, it will increase the burdens of the patients. Therefore, we need to actively prevent the occurrence of subdural effusion after DC. The effectiveness of pressure dressings, as a new method to prevent subdural effusion after DC, has been confirmed. ${ }^{13}$ However, there is a lack of research on the safety of this method. Our study not only further confirms that pressure dressings have a preventive effect on the occurrence of subdural effusion after DC but also further clarifies the safety of this method. Therefore, we suggest that simple and economical pressure dressings can be used to prevent subdural effusion for patients after DC.

\section{Limitations}

Our research has the following shortcomings. First, our study is a retrospective study, which leads to the occurrence of bias. Second, the sample size of this study is small. We did not analyze the patients with ICH and TBI separately, and we could not further study the effect of pressure dressings after DC on the prevention of subdural effusion in patients with ICH and TBI. Third, although our study further confirmed that pressure dressings can reduce the occurrence of subdural effusion after DC, due to the small sample size, we failed to further discuss whether the number of subdural effusions and the duration of effusion disappearance after pressure dressings were shorter than those of traditional dressings. We hope to have a larger sample size and carry out more in-depth research in a future study. Finally, our study is 
only aimed at the prevention of subdural effusion after DC, and whether pressure dressings are effective for patients who have subdural effusion after surgery still needs to be further confirmed by research.

\section{Conclusion}

In our study, for patients with ICH and TBI, the use of a pressure dressing (4-7 days after surgery) after DC prevented the occurrence of subdural effusion. In addition, pressure dressings do not significantly increase the occurrence of other complications related to CSF circulation disorders (CSF leakage and hydrocephalus) after DC. At the same time, pressure dressings can shorten the length of the patient's hospital stay and reduce the costs to the patient during the hospital stay, so the use of pressure dressings can produce better social and economic benefits and reduce the burden on the patient's family. In addition, for the prognosis after DC, pressure dressings did not worsen the patients' outcomes. Pressure dressings a safe and effective; therefore, we recommend pressure dressings in the early postoperative period for patients undergoing DC.

\section{Funding}

Guanghan Science and Technology Bureau's scientific research project in 2020 .

\section{Disclosure}

Joint first authors: Wanyong Huang, Bo Zhou, Yingwei Li. The authors report no conflicts on interest in this work.

\section{References}

1. Honeybul S, Ho KM, Gillett GR. Reconsidering the role of decompressive craniectomy for neurological emergencies. J Crit Care. 2017;39:185-189. doi:10.1016/j.jcrc.2017.03.006

2. Carney N, Totten AM, O'Reilly C, et al. Guidelines for the management of severe traumatic brain injury, fourth edition. Neurosurgery. 2017;80(1):6-15. doi:10.1227/NEU.0000000000001432

3. Kolias AG, Kirkpatrick PJ, Hutchinson PJ. Decompressive craniectomy: past, present and future. Nat Rev Neurol. 2013;9(7):405-415. doi:10.1038/nrneurol.2013.106

4. Hawryluk GWJ, Rubiano AM, Totten AM, et al. Guidelines for the management of severe traumatic brain injury: 2020 update of the decompressive craniectomy recommendations. Neurosurgery. 2020; 87(3):427-434. doi:10.1093/neuros/nyaa278

5. Timofeev I, Czosnyka M, Nortje J, et al. Effect of decompressive craniectomy on intracranial pressure and cerebrospinal compensation following traumatic brain injury. $J$ Neurosurg. 2008;108(1):66-73. doi:10.3171/JNS/2008/108/01/0066

6. Smith M. Refractory intracranial hypertension: the role of decompressive craniectomy. Anesth Analg. 2017;125(6):1999-2008. doi:10.1213/ ANE.0000000000002399
7. Rauen K, Reichelt L, Probst P, et al. Decompressive craniectomy is associated with good quality of life up to 10 years after rehabilitation from traumatic brain injury. Crit Care Med. 2020;48(8):1157-1164. doi:10.1097/CCM.0000000000004387

8. Kurland DB, Khaladj-Ghom A, Stokum JA, et al. Complications associated with decompressive craniectomy: a systematic review. Neurocrit Care. 2015;23(2):292-304. doi:10.1007/s12028015-0144-7

9. Manfiotto M, Mottolese C, Szathmari A, et al. Decompressive craniectomy and CSF disorders in children. Child's Nervous Syst. 2017;33(10):1751-1757. doi:10.1007/s00381-017-3542-7

10. Hayman EG, Kurland DB, Grunwald Z, Urday S, Sheth KN, Simard JM. Decompressive craniectomy in neurocritical care. Semin Neurol. 2016;36(6):508-519. doi:10.1055/s-0036-1592170

11. Sahuquillo J, Dennis JA. Decompressive craniectomy for the treatment of high intracranial pressure in closed traumatic brain injury. Cochrane Database Syst Rev. 2019;12(12):Cd003983.

12. Hejazi N, Witzmann A, Fae P. Unilateral decompressive craniectomy for children with severe brain injury. Report of seven cases and review of the relevant literature. Eur $J$ Pediatr. 2002;161 (2):99-104. doi:10.1007/s00431-001-0864-x

13. Xu GZ, Li W, Liu KG, et al. Early pressure dressing for the prevention of subdural effusion secondary to decompressive craniectomy in patients with severe traumatic brain injury. J Craniofac Surg. 2014;25 (5):1836-1839. doi:10.1097/SCS.0b013e3182a21056

14. Hutchinson PJ, Kolias AG, Timofeev IS, et al. Trial of decompressive craniectomy for traumatic intracranial hypertension. $N$ Engl J Med. 2016;375(12):1119-1130. doi:10.1056/NEJMoa1605215

15. van Middelaar T, Nederkoorn PJ, van der Worp HB, Stam J, Richard E. Quality of life after surgical decompression for space-occupying middle cerebral artery infarction: systematic review. Int J Stroke. 2015;10(2):170-176. doi:10.1111/ijs.12329

16. Mohan Rajwani K, Crocker M, Moynihan B. Decompressive craniectomy for the treatment of malignant middle cerebral artery infarction. $B r \quad J$ Neurosurg. 2017;31(4):401-409. doi:10.1080/ 02688697.2017.1329518

17. Demir O, Deniz FE. A clinical experience with decompressive craniectomy. Turk Neurosurg. 2020;30(5):637-642.

18. Peraio S, Calcagni ML, Mattoli MV, et al. Decompressive craniectomy and hydrocephalus: proposal of a therapeutic flow chart. $J$ Neurosurg Sci. 2017;61(6):673-676. doi:10.23736/S0390-5616. 16.03427-X

19. Haines DE, Harkey HL, Al-Mefty O. The "subdural" space: a new look at an outdated concept. Neurosurgery. 1993;32(1):111-120. doi:10.1227/00006123-199301000-00017

20. Yamashima T. The inner membrane of chronic subdural hematomas: pathology and pathophysiology. Neurosurg Clin N Am. 2000;11 (3):413-424. doi:10.1016/S1042-3680(18)30103-7

21. Wang Y, Wang C, Liu Y. Chronic subdural haematoma evolving from traumatic subdural hydroma. Brain Injury. 2015;29(4):462-465. doi:10.3109/02699052.2014.990513

22. Yang XF, Wen L, Shen F, et al. Surgical complications secondary to decompressive craniectomy in patients with a head injury: a series of 108 consecutive cases. Acta Neurochirurgica. 2008;150(12):12411247; discussion 1248. doi:10.1007/s00701-008-0145-9

23. Liu Y, Gong J, Li F, Wang H, Zhu S, Wu C. Traumatic subdural hydroma: clinical characteristics and classification. Injury. 2009;40 (9):968-972. doi:10.1016/j.injury.2009.01.006

24. Zhou JY, Zhang X, Gao HB, Cao Z, Sun W. Endoscopic-assisted surgery for skull defects with subdural effusion. Wideochirurgia I Inne Techniki Maloinwazyjne. 2021;16(1):219-226. doi:10.5114/ wiitm. 2020.99350

25. Signorelli F, Ioannoni E, Olivi A, Montano N. Factors involved in the development of subdural hygroma after decompressive craniectomy for traumatic brain injury. A systematic review and meta-analysis. J Clin Neurosci. 2020;78:273-276. doi:10.1016/j.jocn.2020.05.033 
26. Martinez-Perez R, Tsimpas A, Rayo N, Cepeda S, Lagares A. Role of the patient comorbidity in the recurrence of chronic subdural hematomas. Neurosurg Rev. 2021;44(2):971-976. doi:10.1007/s10143-020-01274-7

27. Salunke P, Garg R, Kapoor A, Chhabra R, Mukherjee KK. Symptomatic contralateral subdural hygromas after decompressive craniectomy: plausible causes and management protocols. J Neurosurg. 2015;122(3):602-609. doi:10.3171/2014.10.JNS14780
28. Guo H, Zhou X, Li X, Yang S, Wang Y. Scenario for the use of effusion-peritoneal shunt necessary against subdural effusion secondary to decompressive craniectomy. Clin Neurol Neurosurg. 2021;203:106598. doi:10.1016/j.clineuro.2021.106598

\section{Publish your work in this journal}

Neuropsychiatric Disease and Treatment is an international, peerreviewed journal of clinical therapeutics and pharmacology focusing on concise rapid reporting of clinical or pre-clinical studies on a range of neuropsychiatric and neurological disorders. This journal is indexed on PubMed Central, the 'PsycINFO' database and CAS, and is the official journal of The International Neuropsychiatric Association (INA). The manuscript management system is completely online and includes a very quick and fair peer-review system, which is all easy to use. Visit http://www.dovepress.com/testimonials.php to read real quotes from published authors.

Submit your manuscript here: https://www.dovepress.com/neuropsychiatric-disease-and-treatment-journal 